\title{
GASTRONOMSKE MANIFESTACIJE KAO DEO TURISTIČKE PONUDE NEMATERIJALNOG KULTURNOG NASLEĐA SRBIJE
}

\author{
Nataša Kilibarda, \\ Danijel Pavlović, \\ Dušan Borovčanin, \\ Ivana Brdar \\ Univerzitet Singidunum, \\ Beograd, Srbija
}

\begin{abstract}
Rezime:
Kultura ishrane u Srbiji, gastronomija - tradicionalna jela i načini njihove pripreme (tradicionalne tehnologije), kao deo nematerijalnog kulturnog nasleđa, karakterišu se brojnim specifičnostima. Te specifičnosti i raznolikosti postoje zahvaljujući multietničnosti stanovništva Srbije, kao i njenoj burnoj istoriji, što doprinosi kreiranju veoma živopisne kulturne slike kao dela turističke ponude. Gastronomski specijaliteti iz različitih krajeva naše zemlje najčešće se prezentuju kroz gastronomske manifestacije. Zvaničan broj manifestacija ove vrste, prema podacima Turističke organizacije Srbije je 73, iako je taj broj u stvarnosti, verovatno veći. U broju organizovanih gastronomskih manifestacija prednjači region Vojvodine. Budući da su gastronomske manifestacije zapravo spoj tradicije i savremenih trendova, one imaju potencijal da budu jedinstvena i atraktivna turistička ponuda jedne destinacije. U ovom radu analizirane su gastronomske manifestacije kao deo kulturnog nasleđa Srbije. U radu je ukazano na broj gastronomskih manifestacija, njihovu teritorijalnu raspodelu kao i na mogućnosti za razvoj kulturnog turizma uz oslanjanje na nematerijalni deo kulturnog nasleđa Srbije, hranu, gastronomiju i gastronomske manifestacije.
\end{abstract}

Ključne reči:

turizam, kultura, hrana, manifestacije, nematerijalno kulturno nasleđe

UVOD

Nematerijalno kulturno nasleđe, prema definiciji UNESCO-a je „praksa, prezentacija, izražavanje, kao i udružena znanja i neophodne veštine, koje zajednice, grupe i u nekim slučajevima pojedinci prepoznaju kao deo svoje kulturne baštine". Nematerijalna kulturna baština, koja se ponekad naziva i živa kulturna baština, prepoznaje se u sledećim oblastima: usmena tradicija i izrazi, jezik; znanja i primena znanja o prirodi i univerzumu, društvena praksa, rituali i praznici; scenske umetnosti i tradicionalni zanati (UNESCO, 2011). Tradicionalne tehnologije, kao deo tradicionalnih zanata, naročito one koje se koriste u proizvodnji hrane, na primer nekog lokalnog autentičnog specijaliteta, su veoma važna kategorija nematerijalnog kulturnog nasleđa, koje su vezane za životne stilove i na aktuelnim UNESCO-vim listama predstavljene su upravo onako kako se i danas primenjuju u praksi (Gavrilović i Đorđević, 2016). Kako se očuvanjem i prenošenjem nematerijalnog kulturnog nasleđa čuva nacionalni identitet
Correspondence:

Nataša Kilibarda

e-mail:

nkilibarda@singidunum.ac.rs 
jednog naroda, značaj ovog nasleđa, moglo bi se reći, je ozvaničen 2012. godine kada je usvojena Lista elemenata nematerijalnog kulturnog nasleđa Republike Srbije (www.nkns.rs/). Na toj listi se trenutno nalazi 37 elemenata, a od kojih sedam elemenata (približno jedna petina) zapravo predstavljaju jedinstvena nasleđa koja se odnose na hranu i piće, odnosno gastronomske autentične specijalitete, a to su „belmuž“ (ritualno i svakodnevno jelo balkanskih stočara, koje se sprema od mladog ovčijeg sira i kukuruznog brašna), pirotski kačkavalj, pazarske mantije (priprema uz pomoć tradicionalnih tehnologija stanovništva okoline Novog Pazara), rakija Šljivovica, znanje i veština pravljenja kajmaka, „cipovka“ (znanje i umeće pravljenja hleba u Vojvodini), „kuvanje žmara" (tradicionalan način pripreme specijaliteta od ovčjeg mesa karakterističnog u vlaškim selima).

Kultura ishrane u Srbiji, uključujući tradicionalna jela i tehnologije pripreme, predstavlja deo nematerijalnog kulturnog nasleđa i karakterišu je brojne specifičnosti. Te lokalne kulturne specifičnosti, pre svega, potiču od istorijskih tokova i događaja u prošlosti, a koje su uslovljene opet geografskim položajem koji Srbija zauzima. Iz tog razloga u Srbiji se može izdvojiti panonski gastronomski region u Vojvodini, koji je prepoznatljiv po značajnom uticaju evropske kulture, zatim zapadni i centralni gastronomski region, koji je dosta sličan centralnobalkanskom i dinarskom gastronomskom regionu, a najautentičniji su jug i istok Srbije, gde se u smislu ishrane sačuvalo dosta toga iz starobalkanskog kulturnog nasleđa (Dinčić, 2016).

Nematerijalno kulturno nasleđe, održava i razvija i promoviše kulturnu raznolikost i ljudsku kreativnost, čime se čuva i neguje istorija, kultura i tradicija jednog naroda. Iz tog razloga, nematerijalno kulturno nasleđe Srbije budi sve više interesovanja, pre svega lokalnih zajednica, koje su uvidele mogućnost sticanja i materijalne koristi, odnosno ekonomske dobiti, ukoliko bi na pravi način iskoristili svoje nematerijalne kulturne resurse i prezentovali ih u turističke svrhe (Krasojević \& Đorđević, 2015). Naime, turistička promocija lokalnih i regionalnih vrednosti, a među njima i tradicionalnih zanata, koji se odnose na očuvanje izrade gastronomskih specijaliteta, mogla bi da osnaži ekonomske resurse lokalnih zajednica, tako što bi se stimulisao uzgoj domaćih sirovina, njihova prerada i proizvodnja „zdrave“ hrane, prenošenja „znanja“ mlađim generacijama, što bi omogućilo njihovo trajanje, a samim tim i održivost i potencijalni razvoj lokalne zajednice, a to sve uz pomoć prihoda od turizma (Gavrilović \& Đorđević, 2016; Bjeljac et al., 2015).

Kada se Srbija posmatra kao jedinstvena celina, zahvaljujući multietničnosti njenog stanovništva i njihovim specifičnim karakteristikama, može se zaključiti da postoji veoma značajno kulturno nasleđe materijalne, ali i nematerijalne prirode iz različitih civilizacijskih epoha (Bjeljac et al., 2015), čime se može kreirati veoma živopisna kulturna slika Srbije kao deo turističke ponude. Nematerijalna kulturna baština se najčešće i najbolje prezentuju kroz kulturni turizam, odnosno kroz različite manifestacije, kulturne događaje, festivale. Posetom ovakvim događajima, turisti najlakše mogu da otkriju nematerijalno kulturno nasleđe neke turističke destinacije, sa kojim se najverovatnije ne bi susreli, jer im ne bi bilo lako dostupno i „servirano“ na atraktivan način (Cudny, 2013). Poznato je da se gastronomski specijaliteti iz različitih krajeva naše zemlje najčešće prezentuju, upravo kroz gastronomske manifestacije, kao što je na primer Leskovačka roštiljada posvećena leskovačkom roštilju, kao proizvodu zaštićenog geografskog porekla. Ovu gastronomsku manifestaciju, uz četiri manifestacije u Srbiji (muzičkog karaktera) poseti oko dva miliona turista uz ostvaren prihod od oko 30 miliona evra godišnje (Rakočević, 2016). Shodno tome, uočava se jasno prepoznatljiv prostor za proširenje turističke ponude Srbije, kada je u pitanju ponuda autentične i tradicionalne hrane, a samim tim i promocije Srbije i njenog autentičnog nematerijalnog kulturnog nasleđa. Iz tog razloga u ovom radu biće sagledane mogućnosti za unapređenje turističke ponude Srbije, koja se odnosi na gastronomske manifestacije.

\section{HRANA I (KULTURNI) TURIZAM}

Hrana je jedan od ključnih elemenata doživljaja turista, jer je, između ostalog sastavni i obavezni deo svakog putovanja. Brojna istraživanja govore o tome da hrana ima veoma značajan, ponekad čak i presudan uticaj na izbor turističke destinacije (Hall et al., 2003). Usluge prevoza i smeštaja, ubrajaju se u osnovne usluge koje turisti koriste tokom putovanja. U cilju upotpunjavanja turističkog doživljaja tokom putovanja i boravka u turističkoj destinaciji, hrana, posebno kao deo autentične ponude u turističkoj destinaciji, ima značaj koji je izražen u dva faktora: zadovoljavanje osnovnih potreba za ishranom s jedne strane i iskustvo i zadovoljstvo koje proizilazi iz gastronomskog užitka u turističkoj destinaciji., Iako naizgled odvojeni, ovi faktori predstavljaju bitan element ukupnog doživljaja i lanca vrednosti. U prilog tome je i podatak da potrošnja turista za usluge 
hrane i pića može iznositi i do 30\% njihovog ukupnog budžeta koje troše na putovanju (Hall \& Sharples, 2003). Zbog toga se poslednjih godina sve više istražuje i piše na temu turizma hrane (Food tourism). Turizam hrane često je definisan kao poseta primarnim ili sekundarnim proizvođačima hrane, festivalima hrane, restoranima i poseta specifičnim lokalitetima gde se hrana degustira i/ili gde se odlazi da bi se doživela i osetila specifičnost tih lokaliteta i uslova u kojima se proizvodi hrana (Hall \& Mitchell, 2001). Dok za većinu turista hrana predstavlja samo "gorivo“ neophodno za obavljanje osnovnih životnih funkcija (u vezi sa osnovnom životnom potrebom), za određeni broj turista ona predstavlja jedan od osnovnih razloga za putovanje. Između ove dve vrste turista postoje zainteresovani i znatiželjni turisti za hranu u destinaciji. Od velikog značaja za turizam hrane jedne zemlje jeste kreiranje upečatljive slike, koja dugo ostaje u pamćenju turista, kako onih koji ne pokazuju visoku zainteresovanost za hranu, tako i onih kojima hrana nije primarni razlog putovanja, već su samo radoznali da probaju nove, autentične, specijalitete. Mnoge evropske zemlje imaju jasno prepoznatljivu kuhinju, tačnije, ključna jela koja kod turista izazivaju jasnu asocijaciju na konkretnu zemlju. Izvesno je da i turisti koji pokazuju slabo interesovanje za hranu, mogu da povežu pastu, tortilju, picu ili gulaš sa zemljom iz koje potiču i koju predstavljaju. Za Srbiju, kada je u pitanju hrana, utisci turista se uglavnom mogu svesti na fraze poput one „da se u Srbiji dobro jede“ ali i one da su „porcije velike“. Ovde treba imati na umu da su kultura i način življenja pojedinca, u ovom slučaju turiste, nešto što oblikuje njegove želje i potrebe, pa u skladu s tim se izvode i utisci o turističkoj destinaciji, njenim atraktivnostima i posebno hrani, a naročito ako je ona jedinstvena, odnosno autentična. Prepoznatljivost autentičnih specijaliteta, pored toga što nosi marketinšku vrednost, pomaže da se sagradi slika o nekoj turističkoj destinaciji. Da bi se podsticao razvoj prepoznatljivosti nekog gastronomskog specijaliteta (gastronomske ponude) jedne zemlje važna je saradnja državnih organa, turističkih organizacija i lokalnih zajednica, a jedan od ishoda takve saradnje između ostalog bi trebalo da bude, atraktivna i kreativna turistička ponuda. Dobro osmišljena ponuda treba da bude takva da turista poželi pre svega da poseti događaj ili destinaciju, kao i da rezultat tog putovanja bude takav da turista poželi da se vrati u istu destinaciju ili, naročito kada je u pitanju hrana, da gastronomsku ponudu, koja mu ostaje duboko urezana u sećanju kroz autentični doživljaj destinacije, poželi da konzumira i kada se vrati svojoj kući (Hall et al., 2003).

Veza kulture i turizma je u sposobnosti kulture da turizam učini različitim, dok sa druge strane turizam ima sposobnost da podrži materijalno i nematerijalno kulturno nasleđe (OECD, 2008). Kulturni turizam je pojam čiju je definiciju, u užem i širem smislu dala Svetska turistička organizacija (UNWTO) još 1995. godine. U užem smislu kulturni turizam je „kretanje ljudi zbog suštinske motivacije kulturom- studijske ture, izvođačke i druge kulturne ture, , putovanja na festivale i druge kulturne događaje, poseta lokalitetima i spomenicima". U širem smislu kulturni turizam podrazumeva „kretanja ljudi zbog zadovoljavanja potreba za različitošću, usmerena na podizanje kulturnog nivoa pojedinca, obezbeđivanje novih znanja, iskustva i susreta" s drugim kulturama (dopuna autora) (UNWTO, May 2016). Kulturni turizam obuhvata više vrsta turizma: turizam orjentisan na kulturnu baštinu (arheološka nalazišta, spomenici, muzeji itd.), verski turizam, kreativni turizam (na primer, likovne kolonije, izložbe fotografija), gradski turizam, kulturno-tematske rute (uključujući i gastronomske rute), manifestacioni turizam (na primer gastronomske manifestacije), kao i etno turizam (tradicija lokalnih kultura, tradicionalne tehnologije, multietničnost) (Csapo, 2012). Kulturni turizam danas, značajno se razlikuje od onoga što se dominantno podrazumevalo pod kulturnim turizmom tokom druge polovine XX veka. Kako Cvetičanin i drugi navode (2014) kulturni turizam je u svojim počecima bio dominanto usmeren ka materijalnoj kulturnoj baštini, dok je danas sve više usmeren ka kulturnim manifestacijama. Obrazloženje za opšte-rastući pozitivan trend organizovanja kulturnih manifestacija leži i u činjenici što predstavljaju fleksibilniji vid ponude od materijalnog kulturnog nasleđa, te i pružaju snažnije kratkoročne efekte (Richards \& Palmer, 2010), te i da gastronomske manifestacije u značajnoj meri promovišu autentičnost neke destinacije (Baltescu, 2016). S obzirom na vrste kulturnog turizma, uzimajući u obzir i već ono što je istaknuto, a to je da se na listi elemenata nematerijalne kulturne baštine nalazi sedam elemenata - gastronomskih specijaliteta, uočljiva je veza između kulturnog turizma i hrane.

Hrana, kao svojevrsna i specifična ponuda Srbije, zahvaljujući njenoj raznolikosti i specifičnosti, vrlo često se predstavlja turistima kroz različite događaje kulturnog tipa, a najčešće kroz gastronomske manifestacije. Ukoliko se lokalni potencijali, kada su u pitaju hrana i tradicionalne tehnologije, iskoriste na pravi način i učine atraktivnim, kako za turiste, tako i za lokalno stanovništvo, nastaje mogućnost za unapređenje i razvoj turizma, što posebno ima značaja za manje razvijena područja u Srbiji. 


\section{GASTRONOMSKE MANIFESTACIJE U SRBIJI}

Gastronomske manifestacije su manifestacije čiji je nastanak najčešće spontan, što znači da nisu projektovane i osmišljene od strane državnih institucija, već je njihov početak i nastanak kreiran inicijativom pojedinca ili udruženja na lokalnom nivou. Tek kasnije se uvrštavaju u manifestacioni turizam, za koji jesu nadležne institucije javnog i privatnog sektora, kao što su: Ministarstvo trgovine, turizma i telekomunikacija, ali i brojne turističke organizacije i turističke agencije koje organizuju i nude turističke aranžmane u okviru koji je sadržana i poseta nekoj gastronomskoj manifestaciji.

Lista gastronomskih manifestacija koje se održavaju u Srbiji je veoma dugačka, ali je često i nepotpuna. Razlog tome je što se svake godine osmisli i organizuje neka sasvim nova manifestacija posvećena hrani, a opet neke manifestacije se ne održavaju na redovnom, godišnjem nivou, ili se u potpunosti prekine njihova organizacija. Sigurno je da se tačan broj gastronomskih manifestacija koje se održavaju u Srbiji ne može precizno utvrditi. S obzirom na ažurnost podataka, ključni i jedini zvanični izvor, kada su u pitanju gastronomske manifestacije koje se održavaju u Srbiji u 2018. godini je bio Kalendar događaja Turističke organizacije Srbije (Kalendar događaja - TOS, 2018). Prema ovom izvoru u Srbiji je planirano da se u 2018. godini održe 73 gastronomske manifestacije (priredbe), od ukupno 708 događaja, razvrstanih kao opšti događaji, gastronomske priredbe, izvorno narodno stvaralaštvo, pozorišna, literarna, muzička, filmska predstava/likovne kolonije/ kulturni festivali, kongresi/savetovanja, sajmovi/izložbe/berze, promotivne/privredne manifestacije, sportsko rekreativna priredba, praznik/jubilej). Često su gastronomske manifestacije, zapravo prateći sadržaj nekih drugih događaja, kao što su dani kosidbe, berbi grožđa, itd., što takođe doprinosi teškom određivanju tačnog broja manifestacija koje se odnose na hranu. Iz tog razloga, broj gastronomskih manifestacija je sigurno i veći jer figurišu, kao sastavni ili propratni deo različitih festivala, sajmova, manifestacija posvećenih narodnom stvaralaštvu, praznika ili jubileja, najavljenih u Kalendaru događaja Turističke organizacije Srbije (TOS).

Gastronomske manifestacije odnose se na različite neposredne proizvode poljoprivrede, stočarstva, različite proizvode kao i načine spremanja posebnih specijaliteta. Tako postoje slaninijade, pršutijade, kobasicijade, štrudlijade, bostanijade itd (Kovačević, 2010). Kada se analizira, zvaničan broj gastronomskih manifestacija, najavljenih u Kalendaru događaja, a u odnosu na mesto održavanja, zapaža se da se pojedini regioni ističu kada je u pitanju broj organizovanih manifestacija posvećenih hrani. Kako je utvrđeno da se u Srbiji mogu izdvojiti tri regiona koja se prepoznaju po svojim specifičnostima u vrstama jela i načinu pripreme, analizirali smo broj organizovanih manifestacija, za svaki region. Na osnovu zvaničnih podataka i najavljenih događaja, u regionu Vojvodine održava se ukupno 29 manifestacija, odnosno 39.7\% manifestacija od ukupnog broja gastronomskih manifestacija se održava na području Vojvodine, čija površina zauzima svega 24,4 \% ukupne površine Srbije. Zapadni i centralni deo Srbije koji zauzima 29,9\% teritorije Srbije, zvanično organizuje 17 gastronomskih manifestacija ili $23,3 \%$ od ukupnog broja manifestacija. Region Južne i Istočne Srbije zauzima 29,7\% teritorije Srbije, a na njenom području održava se 18 manifestacija, odnosno 24,7\% od ukupnog broja najavljenih gastronomskih manifestaciji u Srbiji. U Beogradu, kao posebnom statističkom regionu Srbije, koji čini 3,7\% teritorije Srbije održava se 9 manifestacija. Jasno je da se iz ovih brojki može zaključiti da je Vojvodina region u Srbiji koja u odnosu na teritoriju koju zauzima, najviše ulaže u organizaciju gastronomskih manifestacija. Iako teritorijalni obuhvat nije osnovni i jedini indikator većeg broja ovakvih manifestacija, potrebno je istaći da raznovrsnost kultura u određenom geografskom području može doprineti i većem broju manifestacija ovog tipa.

Uzimajući u obzir geografski položaj Srbije, kroz istoriju, ona se nalazila na meti mnogih osvajača. Kako se pisala istorija, tako se formirala i kreirala srpska kuhinja. Upravo zbog uticaja i mešanja različitih kultura, pre svega orijentalnih i srednjoevropskih, koje su donosili osvajači sa sobom, boraveći kraće ili duže na našim prostorima, nastajala je srpska kuhinja, za koju se teško može reći da je autohtona, ali se zato može reći da je jedinstveno, ukusno i zanimljivo baš zbog toga što je receptura napisana jezikom mnogih kultura.

Gastronomska ponuda Vojvodine se umnogome razlikuje od ostalih regiona u Srbiji. Pre svega zbog toga, što je kroz istoriju bila izložena srednjoevropskom uticaju, odnosno uticaju nemačke, mađarske, austrijske i slovačke kuhinje. U Vojvodini su karakteristična testa (gomboci, rezanci, gibanice, hlebovi, štrudle), sva vrsta rezanaca "nasuvo“ (sa makom, sa sirom itd.). Meso se kuva u sosu, spremaju se gulaši sa svinjskim mesom, riblji paprikaši, a posebno je interesantna u Bačkoj gastronomska ponuda kiselo-slatkih ukusa u jelima, kao i 
proizvodi od mesa, naročito fermentisane kobasice, kao što je kulen, na primer. Iako, Vojvodina na Listi nematerijalnog kulturnog nasleđa ima predstavljenu cipovku, kao vrstu hleba koja se jedino pravi u Vojvodini na specifičan i jedinstven način, u zvaničnom kalendaru gastronomskih manifestacija, ne postoji nijedan događaj posvećen cipovki, što opet ne znači i da se takve manifestacije ne organizuju, već samo da nisu pozicionirane na tržištu i dovoljno prepoznate i promovisane. Na popularnom sajtu Gastrovodič (www.gastrovodic.rs) koji se bavi aktuelnim temama iz gastronomije, data je preporuka za deset gastronomskih manifestacija u Srbiji koje treba posetiti. U Vojvodini su to Slaninijada u Kačarevu kod Pančeva, Kobasicijada u Turiji, koje između ostalog imaju i dugačku tradiciju održavanja (preko dvadeset godina), kao i Kulenijada u Erdeviku.

Pod Centralnom i Zapadnom Srbijom podrazumevamo oblast između Drine i Velike Morave, a na jugu do Kraljeva, odnosno do Zapadne Morave. Šumadijska kuhinja i kuhinja Zapadne Srbije su najmanje bile izložene stranim uticajima. Ovo područje karakteriše najveći broj jela koje se već danas mogu nazvati brendovima Srbije. Za njih su karakteristične različite vrste pita, posebno zeljanica, proje, projare, heljdopite, kao i meso pečeno na ražnju. U Zapadnoj Srbiji najveći specijalitet je sušeno meso, a na Zlatiboru i Zlataru izdvajaju se i jela od jagnjetine. U užičkom kraju posebno je popularna čuvena komplet lepinja (u već pečenu lepinju razbije jaje koje se pomeša sa starim kajmakom). Mleko i mlečni proizvodi imaju kultni status u Zapadnoj Srbiji i Šumadiji, a posebno se izdvajaju sjenički, zlatarski, zlatiborski kraljevački sir i kajmak. Najveća etnička raznolikost primećuje se u Raškoj oblasti (Sandažku) posebno novopazarskom kraju, gde većinu stanovništva čini stanovništvo muslimanske veroispovesti, što je direktno uticalo da se svinjetina ne konzumira. Svakako, ovo područje ima bogatu kuhinju u kojoj se najviše ističu ćevapi, mantije (vrsta pita od mesa), stelje (suhomesnati proizvodi od ovčijeg mesa), sudžuk i sl. Za područje Centralne i Zapadne Srbije karakteristična su šljivovica (regularno ili kuvana), klekovača i rakija od maline (Drašković, 20185). Međutim, u Kalendaru događaja TOSa, ne postoje zakazane manifestacije posvećene jelima, karakterističnim za ovaj kraj, a koje se nalaze na Listi elemenata nematerijalnog kulturnog nasleđa (veština pravljenja kajmaka i pazarske mantije) (www.nkns.rs/). Ipak na sajtu „Gastrovodič“ kao preporuku za posetu nalaze se manifestacije ovog regiona, kao što su Pršutijada u Mačkatu na Zlatiboru, Kupusijada u Mrčajevcima i Festival duvan čvaraka koji se održava u Valjevu.

Istočna Srbija je zbog očuvanih prirodnih lepota i prisutnog multietničnog stanovništva potencijalno značajna turistička destinacija. Specifičnosti ove regije ogledaju se i u gastronomskoj ponudi, koju karakterišu jela, koja su i dalje nedovoljno istražena, jedinstvena, neotkrivena i samim tim vrlo primamljiva. Jedinstvenost ovih jela u Srbiji zapravo je uticaj vlaške nacionalne manjine, čiju kulturu karakteriše prisustvo mistike, što se svakako odražava i na kuhinju ove regije, čineći je vrlo atraktivnu za turiste sa drugih prostora. Najznačajniji proizvodi sa ovih prostora su homoljski proizvodi, kao što je homoljski med od lekovitog bilja, homoljski sir (koji se pravi od kravljeg, kozijeg ili ovčijeg mleka) i homoljsko jagnje na ražnju (Drašković, 2018). Na jugu Srbije posebno se ističu jela od paprike, kao što je ajvar, a naravno i roštilj u Leskovcu, zatim čorbe pune povrća i blago ljutog do ljutog ukusa. Osim ajvara, vrlo su prepoznatljivi i pindžur, ljutenica i turšija. Na Listi elemenata nematerijalnog kulturnog nasleđa Srbije iz ovog kraja nalazi se belmuž i pirotski kačkavalj, a manifestacije posvećene ovim specijalitetima najavljene su u Kalendaru događaja. Gastronomska manifestacija - Kuvanje žmara, vlaškog specijaliteta, koji se takođe nalazi na Listi nematerijalnog kulturnog nasleđa Srbije verovatno postoji kao deo neke etno manifestacije, ali u dostupnom Kalendaru događaja ovakva manifestacija nije posebno naznačena. Popularni sajt iz oblasti gastronomije, „gastrovodič“, preporučuju posetu Sajmu peglane kobasice u Pirotu, Danima Banice (banica - vrsta pite) u Beloj Palanci, kao i Vurdijada (vurda je proizvod od mleka) u Babušnici.

Iz svega navedenog može se zaključiti da su poželjni adekvatniji pristupi u sveobuhvatnijoj promociji gastronosmkih manifestacija i tzv. gastronomskog užitka u turizmu Srbije. Jedan od pristupa podrazumevao bi i širu logistiku i veće ekonomske resurse kako bi se uspešno organizovale i promovisale gastronomske manifestacije, posebno one koje se odnose na autentična srpska jela istaknuta na Listi nematerijalnog kulturnog nasleđa Srbije.

\section{SAGLEDAVANJE EFEKATA GASTRONOMSKIH MANIFESTACIJA KAO VIDA KULTURNOG TURIZMA}

Podaci o poseti gastronomskim manifestacijama u Srbiji, uglavnom potiču iz novinskih članaka, a koji govore o tome da ovakve manifestacije privlače veliki broj turista. Da bi se utvrdili broj i struktura posetilaca, njihova potrošnja, potrebna su obimna i detaljna istraživanja. Zato, oslanjajući se opet na dostupne informacije, 
može se zaključiti da za gastronomske manifestacije postoji značajno interesovanje, kao i da manifestacijama ove vrste prisustvuju, kako lokalno stanovništvo, tako i turisti iz drugih krajeva zemlje, te i stranci, kako ono koji predstavljaju srpsku dijasporu, tako i stranci uopšte. U iščekivanju podataka koji bi se dobili iz neke opsežnije studije, o broju i strukturi turista, njihovoj potrošnji kao i prihodima, možemo zauzeti stanovište, koje je zapravo i polazna pretpostavka u velikom broju naučnih radova i udžbenika, da manifestacije kao sastavni deo onoga što se definiše kao kulturni turizam mogu proizvesti povoljne efekte. Najčešće se podrazumevaju povoljni materijalni ili ekonomski efekti, ali ne retko i drugi nematerijalni efekti poput jačanja kulturnog i obrazovnog nivoa stanovništva, izgradnje ili popravljanja ugleda određene destinacije itd. Jedan od interesantnijih zaključaka istraživanja o vezi kulturnog turizma bio je zaključak iz istraživanja koje su sproveli (Warren \& Brian , 2000) a to je da oni posetioci čiji primarni razlog nije bio poseta manifestaciji, ali su svoj boravak zbog nje produžili, najveći deo svojih sredstava dodatno potrošili na usluge hrane i pića u restoranima.

Dalje, održavanje gastronomskih manifestacija u nekoj turističkoj destinaciji, u trajanju od više dana, sigurno da ima pozitivne efekte i u oblasti hotelijerstva, u smislu većeg broja gostiju i ostvarivanju većeg broja noćenja, što nesumnjivo znači veću ekonomsku dobit. Primarni izvor prihoda i profitabilnosti u hotelijerstvu je sektor smeštaja. Učešće ovog sektora u ukupnim prihodima je na nivou $69.2 \%$ dok je profitabilnost samog sektora na nivou od 78.5\% (Barjaktarović, 2015). Međutim, u hotelu, hrana i piće su odavno prestali da budu sektor koji samo proizvodi troškove. Više od dve decenije radi se o sektoru koji stvara i značajan izvor prihoda i generiše deo profita na kraju godine. (Adler \& Tzu Chu, 2008). Prema podacima kompanije STR Global, ranije poznata kao Smith Travel Research, koji predstavljaju svetske lidere u prikupljanju podataka u međunarodnom hotelijerstvu, na primeru tržišta Ujedinjenog kraljevstva podaci ukazuju da je udeo prihoda od hrane i pića u ukupnom prihodu korporativnih hotela $27 \%$ u proseku u 2015. godini, dok je profitabilnost unutar samog sektora hrane i pića na primer korporativnih hotela na tržištu Budimpešte na nivou od 34.1\% (STR, 2018). Ovi podaci govore u prilog tome, da hoteli u destinaciji u kojoj se održavaju manifestacije kulturnog tipa, a posebno one posvećene gastronomskim autentičnim specijalitetima, treba da posebnu pažnju i dodatne aktivnosti usmere ka implementaciji i održavanju i unapređenju standarda iz oblasti bezbednosti hrane i svoju ponudu kreiraju tako da bude $u$ duhu gastronomske ponude Srbije. To bi dodatno trebalo da doprinese kreiranju slike i imidža Srbije na gastronomskoj mapi regiona, Evrope i sveta o čemu bi „dobar glas“ preneli zadovoljni posetioci.

Može se reći da su gastronomske manifestacije delimično prisutne u ponudi turističkih agencija, a to svakako predstavlja znak, da je prepoznat potencijal ovih manifestacija. Ono što je nedostatak jeste to što ne postoje programi turističkih agencija, koji bi omogućili posetu većem broju ovakvih manifestacija u okviru jednog turističkog aranžmana. Sa druge strane, kao ograničenje u kreiranju takvih aranžmana javlja se vremensko određivanje termina održavanja ovakvih manifestacija (gde je čest slučaj da dolazi do preklapanja termina različitih manifestacija sa manifestacijama koje se istovremeno održavaju u drugim destinacijama). Posebno je značajno da termin održavanja gastronomskih manifestacija bude usaglašen sa terminom održavanja nekog „poznatog" i popularnog festivala (događaja) u istoj destinaciji, čime bi se obezbedio veći broj posetilaca.

Nedvosmisleno je da pozitivni efekti, kako materijalni tako i nematerijalni efekti održavanja gastronomskih manifestacija postoje. Međutim postoje i problemi, koje su utvrdili Cvetičanin i drugi., (2014) kada su sproveli studiju o kulturnim manifestacijama u Vojvodini. Identifikovani problemi, kada su u pitanju organizacija i održavanje kulturnih manifestacija svrstani su u tri grupe: prva grupa problema su strateške prirode i obuhvataju nedostatak dugoročnog finansiranja manifestacija, nedefinisane strategije razvoja kulturnog turizma, zatim neažurne kalendare događaja i preklapanje termina održavanja manifestacija; druga grupa problema je nedostatak saradnje između institucija i organizacija na lokalnom nivou, kao i neprepoznavanje značaja ovih manifestacija u turističkoj ponudi Srbije; treća grupa problema odnosi se i na nekompetentnost onih koji učestvuju u kreiranju i organizaciji kulturnih manifestacija.

\section{ZAKLJUČAK}

Uloga javnog i privatnog sektora koji se bavi turizmom, jeste da zajednički, i između ostalog ekonomskim merama, kreiraju, potpomažu, usmeravaju i unapređuju turističku ponudu Srbije. U skladu sa postojećim resursima koje Srbija poseduje i u skladu sa trendovima na međunarodnom i domaćem tržištu jasno je da 
resursi turističke destinacije sami po sebi često nisu dovoljan razlog da turisti posete određenu destinaciju, već je neophodno kreiranje adekvatne ponude i zaokruživanje turističkog proizvoda u cilju kreiranja doživljaja kao osnovnog, fundamentalnog proizvoda u turizmu (Popesku i Pavlović, 2013, str. 200; Pavlović, Avlijaš i Stanić, 2016, str. 1). Kada su gastronomske tradicije u pitanju one se ne shvataju kao nešto što je dato, već se iz njih crpe ideje, i kreiraju događaji, koji se integrišu u turističku ponudu destinacije. Ovakav kreativan i inovativan pristup organizaciji gastronomskih manifestacija, omogućava to da one treba da predstavljaju spoj tradicije i savremenih tokova, i na taj način predstave nešto „staro“ a novo, što svakako, rezultira nečim što je jedinstveno, atraktivno i drugačije. Konkurentne destinacije koje sadrže elemente gastronomije kao nematerijalnog kulturnog nasleđa su one koje nude karakteristične, autentične i jedinstvene gastronomske specijalitete, na takav način da ih to razlikuje od konkurentskih destinacija, nudeći doživljaj gastronomskog užitka bolje i učinkovitije od drugih turističkih destinacija. Moderno aranžiranje srpskih jela uz primenu novih tehnologija pripreme hrane je jedan od načina stvaranja upečatljive gastronomske ponude Srbije koja postaje tražena, koja se pamti i prepričava, a koja je važan deo kulturnog nasleđa Srbije kao turističke destinacije

\section{LITERATURA}

Adler, H., \& Tzu Chu, C. (2008). The Wedding Business: A Method to Boost Food and Beverage Revenues in Hotels. Journal of foodservice business research, 7(1), 117-125. DOI: 10.1300/J369v07n01_08

Baltescu, C.A. (2016). Culinary experiences as a key tourism attraction. Case Study: Braşov County. Bulletin of the Transilvania University of Braşov Series V: Economic Sciences, 9(58), 107-112.

Barjaktarović, D. (2015). Upravljanje kvalitetom u hotelijerstvu. Beograd: Univerzitet Singidunum.

Bjeljac, Ž., Terzić, A. \& Lovrić, S. (2015). Nematerijalno kulturno nasleđe u Srbiji kao turistički brend. Turističko poslovanje, 15, 53-61.

Csapo, J. (2012). The Role and Importance of Cultural Tourism in Modern Tourism Industry. In: Dr. Murat Kasimoglu (Ed.), Strategies for Tourism Industry - Micro and Macro Perspectives, (pp. 201-231). InTech, Available from: http://www.intechopen.com/books/strategies-for-tourism-industry micro-and-macroperspectives/ the-role-and-importance-of-cultural-tourism-in-modern-tourism-industry.

Cudny, W. (2013). Festival tourism: The concept, key functions and dysfunctions in the context of tourism geography studies. Geographical Journal, 65(2), 105-118.

Cvetičanin, P., Mišković, I., Milošević, S., \& Škrbić, I. (2014). Diferenciranje kulturnih manifestacija u cilju razvoja kulturnog turizma $u$ Vojvodini. Novi Sad: Fakultet za sport i turizam.

Dinčić, A. (2016). Kultura ishrane u Srbiji. Preuzeto 20.8.2018.

http://www.rts.rs/page/magazine/sr/story/2523/nauka/2543840/kultura-ishrane-u-srbiji.html

Drašković S. (2018). Međunarodna gastronomija. Beograd : Univerzitet Singidunum.

Gavrilović, Lj., \& Đorđević, I. (2016). Sjenički sir kao nematerijalno kulturno nasleđe: Antropološki pristup problemu. Etnoantropološki problemi, 11(4), 989-1004.

Hall, C.M, \& Sharples, L. (2003). The consumption of experiences or the experience of consumption? An introduction to the tourism of taste. In C. Hall, L. Sharples, \& R. Mitchell, Food Tourism Around the World: development, management and markets (pp. 1-13). Oxford: Butterworth-Heinemann.

Hall, C.M., \& Mitchell, R. (2001). Wine and food tourism. In Special Interest Tourism: Context and Cases Douglas, N., Douglas, N. and Derrett, R. (Eds), pp. 307-329, Wiley.

Kovačević, I. (2010). Gastronomske tradicije. U: Miloš Milenković (ur.), Etnoantropološki problemi (str. 59-107). Beograd: Odeljenje za etnologiju i antropologiju, Univerzitet u Beogradu, Filozofski fakultet.

Krasojević, B. \& Đorđević, B. (2015). Nematerijalno kulturno nasleđe: turistički resurs Srbije U: Međunarodna naučna konferencija iz oblasti informacionih tehnologija i savremenog poslovanja, 16-17. april, (561-565). Beograd: Univerzitet Singidunum.

NKNS. (2018). Lista elemenata nematerijalnog kulturnog nasleđa Republike Srbije. Dostupno: septembar 2018 na: www.nkns.rs/

OECD. (2008). The Impact of Culture on Tourism. OECD.

Pavlović, D., Avlijaš, G., \& Stanić, N. (2016). Tourist perception as key indicator od destination competitiveness. Teme: Časopis za društvene nauke, 40(2), 853-868. 
Popesku, J., \& Pavlović, D. (2013). Competitiveness of Serbia as a tourist destination: Analysis of selected key indicators. Marketing, 44(3), 199-210.

Rakočević, J. (2016). Dobra zarada od turističkih manifestacija u Srbiji. Prezuzeto, 20.08.2018. http://www.rts. rs/page/stories/sr/story/13/ekonomija/2432536/dobra-zarada-od-turistickih manifestacija-u-srbiji.html

Richards, G., \& Palmer, R. (2010). Eventful Cities: Cultural management and urban revitalisation. ButterworthHeinemann.

STR (2018). STR Global. Preuzeto, avgust 25, 2018, sa https://www.strglobal.com/

TOS (2018). Kalendar događaja. Dostupno: septembar 2018 na: http://www.srbija.travel/dogadjaji/kalendar-dogadjaja.36.html

UNESCO (2011). Infokit 2011: What is Intangible Cultural Heritage? Retrieved, September 2018 from: https:// ich.unesco.org/en/what-is-intangible-heritage-00003

UNWTO (May, 2016). Concept Note, International Seminar on Tourism and Culture. Retrieved, September 2018 from: http://cf.cdn.unwto.org/sites/all/files/pdf/concept_note_international_seminar_tourism_and_culture_en_1.pdf

Warren, M., \& Brian, R. (2000). Practical Issues in Measuring the Impact of a Cultural Tourist Event in a Major Tourist Destination. Journal of Travel Research, 300-303. DOI: 10.1177/004728750003800313

\title{
GASTRONOMIC MANIFESTATION AS PART OF TOURIST OFFER OF INTANGIBLE CULTURAL HERITAGE OF SERBIA
}

\begin{abstract}
:
Gastronomic culture in Serbia, traditional dishes and their ways of preparation (traditional technologies), as part of intangible cultural heritage, are characterized by numerous specific qualities. These qualities and diversity exist thanks to the multi-ethnicity of the Serbian population, as well as its turbulent history, which contributes to the creation of a pretty picturesque cultural image as part of the tourist offer. It is through gastronomic events that gastronomic specialties from different parts of the country are usually/most often presented. The official number of events of this kind, according to the National Tourism Organization of Serbia, is 73, although in reality, this number is probably larger/ more substantial. The region of Vojvodina is at the forefront according to the number of organized gastronomic events. Since gastronomic events are in fact a combination of tradition and contemporary trends, they have potential to be a unique and attractive tourist offer of a destination. In this paper, gastronomic manifestations were analyzed as part of Serbia's cultural heritage. This paper presents the number of gastronomic events and their territorial distribution. Moreover, the aim of this paper is to point to the possibilities for the development of cultural tourism, in accordance to the intangible cultural heritage of Serbia, food, gastronomy and gastronomic events.
\end{abstract}

Keywords:

tourism, culture, food, manifestations, intangible cultural heritage 